\title{
Observing carbon dioxide emissions over China's cities and industrial areas with the Orbiting Carbon Observatory-2
}

\author{
Bo Zheng ${ }^{1}$, Frédéric Chevallier ${ }^{1}$, Philippe Ciais ${ }^{1}$, Grégoire Broquet ${ }^{1}$, Yilong Wang ${ }^{1,2}$, Jinghui Lian $^{1}$, and \\ Yuanhong Zhao ${ }^{1}$ \\ ${ }^{1}$ Laboratoire des Sciences du Climat et de l'Environnement, CEA-CNRS-UVSQ, UMR8212, Gif-sur-Yvette, France \\ ${ }^{2}$ Key Laboratory of Land Surface Pattern and Simulation, Institute of Geographical Sciences and Natural Resources \\ Research, Chinese Academy of Sciences, Beijing, China
}

Correspondence: Bo Zheng (bo.zheng@1sce.ipsl.fr)

Received: 12 February 2020 - Discussion started: 24 February 2020

Revised: 22 June 2020 - Accepted: 29 June 2020 - Published: 21 July 2020

\begin{abstract}
In order to track progress towards the global climate targets, the parties that signed the Paris Climate Agreement will regularly report their anthropogenic carbon dioxide $\left(\mathrm{CO}_{2}\right)$ emissions based on energy statistics and $\mathrm{CO}_{2}$ emission factors. Independent evaluation of this self-reporting system is a fast-growing research topic. Here, we study the value of satellite observations of the column $\mathrm{CO}_{2}$ concentrations to estimate $\mathrm{CO}_{2}$ anthropogenic emissions with 5 years of the Orbiting Carbon Observatory-2 (OCO-2) retrievals over and around China. With the detailed information of emission source locations and the local wind, we successfully observe $\mathrm{CO}_{2}$ plumes from 46 cities and industrial regions over China and quantify their $\mathrm{CO}_{2}$ emissions from the OCO-2 observations, which add up to a total of $1.3 \mathrm{GtCO}_{2} \mathrm{yr}^{-1}$ that accounts for approximately $13 \%$ of mainland China's annual emissions. The number of cities whose emissions are constrained by OCO-2 here is 3 to 10 times larger than in previous studies that only focused on large cities and power plants in different locations around the world. Our satellite-based emission estimates are broadly consistent with the independent values from China's detailed emission inventory MEIC but are more different from those of two widely used global gridded emission datasets (i.e., EDGAR and ODIAC), especially for the emission estimates for the individual cities. These results demonstrate some skill in the satellite-based emission quantification for isolated source clusters with the OCO-2, despite the sparse sampling of this instrument not designed for this purpose. This skill can be improved by future satellite missions that will have a
\end{abstract}

denser spatial sampling of surface emitting areas, which will come soon in the early 2020 s.

\section{Introduction}

The Paris Agreement on climate change requires all parties (countries) to report their anthropogenic greenhouse gas emissions and removals at least every 2 years within an enhanced transparency framework (UNFCCC, 2018). Then, starting in 2023, the country reports will periodically form the basis for a global stocktake that will assess collective progress in bringing the global greenhouse gas emissions consistent with global warming well below $2{ }^{\circ} \mathrm{C}$ above preindustrial levels. In order to address potential biases in this self-reporting mechanism, the contribution of independent observation systems is being increasingly sought (IPCC, 2019). Our focus here is on the direct observation of fossil fuel carbon dioxide $\left(\mathrm{CO}_{2}\right)$ emission plumes from space and on the quantification of $\mathrm{CO}_{2}$ emissions from this observation independently.

NASA's second Orbiting Carbon Observatory (OCO-2) polar satellite (Eldering et al., 2017) is one of the best existing instruments for the retrieval of column-averaged dryair mole fraction of $\mathrm{CO}_{2}\left(\mathrm{XCO}_{2}\right)$. It observes the clear-sky and sunlit part of the Earth with footprints of a few square kilometers $(1.29 \mathrm{~km} \times 2.25 \mathrm{~km})$ gathered in a $\sim 10 \mathrm{~km}$ wide swath for each orbit, particularly suitable for informing natural $\mathrm{CO}_{2}$ budgets at the continental scale. It has already acquired more than 5 years of science data since its launch 
in July 2014, which have provided initial insight into carbon fluxes from the tropical terrestrial ecosystems (Liu et al., 2017; Palmer et al., 2019) but not without ambivalence due to likely significant residual systematic errors in the OCO-2 $\mathrm{XCO}_{2}$ retrievals (Chevallier, 2018).

Extending the use of OCO-2 to monitor fossil fuel $\mathrm{CO}_{2}$ emissions is rather challenging because the excess $\mathrm{XCO}_{2}$ generated by large cities or power plants typically reaches $\sim 1 \%$ at best (Kort et al., 2012), which is about $4 \mathrm{ppm}$ compared with an instrument noise typically around 0.3$0.6 \mathrm{ppm}$ (Worden et al., 2017) for a single sounding. This non-negligible noise in the $\mathrm{XCO}_{2}$ retrievals is hardly balanced by the amount of data sampled near emission sources with a narrow swath, which hampers the detection of emission plumes and the precision of emission quantification. Only under rare occasions do the OCO-2 tracks cross $\mathrm{CO}_{2}$ plumes downwind of large cities (Labzovskii et al., 2019; Reuter et al., 2019) or power plants (Schwandner et al., 2017; Nassar et al., 2017; Zheng et al., 2019), limiting the possibility to quantify the corresponding $\mathrm{CO}_{2}$ emissions to a few cases within a year. So far, studies on the potential of spaceborne $\mathrm{CO}_{2}$ observations to infer $\mathrm{CO}_{2}$ emissions from large cities or power plants have relied on Observing System Simulation Experiments (OSSEs) (Bovensmann et al., 2010; O'Brien et al., 2016; Broquet et al., 2018; Kuhlmann et al., 2019; Wang et al., 2020) and on several well-chosen cases with real OCO-2 retrievals (Nassar et al., 2017; Reuter et al., 2019; Zheng et al., 2019; Wu et al., 2020). To our knowledge, no attempt has been made yet to infer anthropogenic emissions from actual OCO-2 data over a large area or a long period to evaluate a large-scale $\mathrm{CO}_{2}$ budget.

Here we analyze all OCO-2 ground tracks between September 2014 and August 2019 over and around China, which is the largest emitter country in the world, in order to quantify $\mathrm{CO}_{2}$ anthropogenic emissions at a large spatial extent over China. We develop a novel, simple, and effective approach to identify the $\mathrm{CO}_{2}$ plumes from isolated emission clusters, to relate them unambiguously to nearby human emission sources, and to estimate the $\mathrm{CO}_{2}$ emission fluxes causing each plume. The 5-year period allows nearly onesixth of all the emissions from mainland China to be observed, although OCO-2 swaths have a low probability of crossing the emission plume from a given city. The budget of $\mathrm{CO}_{2}$ emissions aggregating all the sources inferred from the satellite is compared to different emission inventories compiled by multiplying fuel consumption statistics by emission factors. Such a comparison, for the first time covering a significant fraction of the emissions from a country, demonstrates the potential of independently evaluating the self-reporting emission inventories from space.

\section{Data and method}

\subsection{Data input}

We use version 9r of the OCO-2 bias-corrected $\mathrm{XCO}_{2}$ retrievals (Kiel et al., 2019). We use the good-quality data (xco2_quality_flag equals 0 ) over both land and ocean and associated retrieval uncertainty statistics. Our inversion framework relies on auxiliary information about winds and about the spatial distribution of emission sources, which are jointly used to link the observed $\mathrm{CO}_{2}$ plume section with upwind local emission sources. We choose the spatially explicit Multi-resolution Emission Inventory for China (MEIC) dataset (Zheng et al., 2018a, b) that provides the locations of $\sim 100000$ individual industrial point sources ( $82 \%$ of mainland China emissions) and $0.1^{\circ} \times 0.1^{\circ}$ area source emissions (18\% of mainland China emissions) developed for the year 2013. Unlike other inventories used to map industrial emissions using spatial proxies, MEIC includes local reports from each power plant and industrial operator about their emissions and geographic locations. The ERA5 reanalysis data (C3S, 2017) provide us with a first guess for the local wind fields.

\section{$2.2 \quad \mathrm{OCO}-2 \mathrm{XCO}_{2}$ local enhancement}

The key steps of our method are the identification of an $\mathrm{XCO}_{2}$ local enhancement from the satellite data that can be attributed to a $\mathrm{CO}_{2}$ plume from a large emission source, its separation from the surrounding background, and the establishment of a numerical link to the nearby upwind human emission sources. They are designed to account for the specificity of the sampling capability of OCO-2 and for the $\mathrm{XCO}_{2}$ retrieval errors.

First, we look for $\mathrm{XCO}_{2}$ anomalies along the OCO-2 tracks, which exceed $2 \sigma$ of the spatial variability above the local average within $200 \mathrm{~km}$ wide moving windows centered on the locations of the anomalies. These anomalies potentially belong to significant $\mathrm{CO}_{2}$ plumes. In each window corresponding to such an anomaly and with more than 200 highquality retrievals (with $\sim 800$ retrievals if none are missing due to cloud contaminations or other issues in the retrieval algorithm), the following curve fitting is applied to the $\mathrm{XCO}_{2}$ retrieval data along the OCO-2 track:

$y=m \cdot x+b+\frac{A}{\sigma \sqrt{2 \pi}} e^{\left[-(x-\mu)^{2} / 2 \sigma^{2}\right]}$,

where $y$ is $\mathrm{XCO}_{2}(\mathrm{ppm}) ; x$ is the distance $(\mathrm{km})$ along the OCO-2 track in a fitting window; and $m, b, A, \mu$, and $\sigma$ are parameters that determine the curve shape, estimated by a nonlinear least-squares fit weighted by the reciprocal of $\mathrm{XCO}_{2}$ uncertainty statistics. The linear part $m \cdot x+b$ represents the background level assuming the background is linear (Reuter et al., 2019), while the remaining part depicts a single $\mathrm{XCO}_{2}$ peak with a Gaussian shape (Nassar et al., 2017). Several $\mathrm{XCO}_{2}$ anomalies should belong to the same $\mathrm{CO}_{2}$ plume: 
in order to only define a single equation for a given plume and the corresponding background, we fit the curve around each $\mathrm{XCO}_{2}$ anomaly and select the one with the largest $R^{2}$. We also reject all cases with low $R^{2}$ (less than 0.25 ) to achieve better fitting performance.

Second, we select the cases when the range of $\mu \pm 3 \sigma$ is fully covered by the $200 \mathrm{~km}$ window to achieve complete fitting curves that cover both the plume part and the wide range of local background. To make the curve fitting robust, we further select the observational cases that have at least three valid cross-track footprints (eight footprints if none are missing) on average within the plume transect $(\mu \pm 2 \sigma)$ to constrain the shape of the fitted curve with enough data points. Finally, we check if the parameter $A$ is positive and if the average $\mathrm{XCO}_{2}$ value within the plume (defined as the average of raw $\mathrm{XCO}_{2}$ retrievals within $\mu \pm 2 \sigma$ ) minus the surrounding background concentration (derived as the average of raw $\mathrm{XCO}_{2}$ retrievals outside $2 \sigma$ ) is larger than the standard deviation of the background values within $200 \mathrm{~km}$. Only the cases that pass these two filtering criteria are finally identified as the $\mathrm{XCO}_{2}$ local enhancements in this study.

\subsection{Gaussian plume model}

We use the Gaussian plume model (Bovensmann et al., 2010) to attribute the observed $\mathrm{XCO}_{2}$ enhancement to a neighbor cluster of emission sources. We simulate the sum of $\mathrm{XCO}_{2}$ plumes generated by each point source and each emission grid cell from the MEIC inventory within $50 \mathrm{~km}$ of the studied OCO-2 track with the equations

$$
\begin{aligned}
& V=\sum_{\in 50 \mathrm{~km}} \frac{F}{\sqrt{2 \pi} \cdot a \cdot z^{0.894} \cdot u} e^{-\frac{1}{2}\left(\frac{n}{a \cdot z^{0.894}}\right)^{2},} \\
& \mathrm{XCO}_{2}=V \cdot \frac{M_{\mathrm{air}}}{M_{\mathrm{CO}_{2}}} \cdot \frac{g}{P_{\text {surf }}-w \cdot g} \cdot 1000,
\end{aligned}
$$

where $V$ is the $\mathrm{CO}_{2}$ vertical column $\left(\mathrm{g} \mathrm{m}^{-2}\right)$ downwind of the emission sources, $F$ is the emission rate $\left(\mathrm{g} \mathrm{s}^{-1}\right), u$ is the wind speed $\left(\mathrm{m} \mathrm{s}^{-1}\right), z$ is the along-wind distance $(\mathrm{km}), n$ is the across-wind distance $(\mathrm{m})$, and $a$ is the atmospheric stability parameter. Equation (3) converts $V\left(\mathrm{~g} \mathrm{~m}^{-2}\right)$ to $\mathrm{XCO}_{2}$ (ppm), where $M$ is the molecular weight $\left(\mathrm{kg} \mathrm{mol}^{-1}\right), g$ is the gravitational acceleration $\left(\mathrm{m} \mathrm{s}^{-2}\right), P_{\text {surf }}$ is the surface pressure $(\mathrm{Pa})$, and $w$ is the total column water vapor $\left(\mathrm{kg} \mathrm{m}^{-2}\right)$.

$F$ is derived from the MEIC emission inventory (Zheng et al., 2018b), including both point sources and $0.1^{\circ} \times 0.1^{\circ}$ area source emissions. Each grid cell of area sources is used as a point source in Eq. (2). $u$ is the average wind at 1000, 975, and $950 \mathrm{hPa}$ to approximate the wind below $500 \mathrm{~m}$ (Beirle et al., 2011) at the time of the OCO-2 overpass, derived from the ERA5 reanalysis data (C3S, 2017). In the presence of relief, the average of the pressure-level winds is weighted towards the surface. $a$ is a function of the atmospheric stability condition (Martin, 1976) determined by both the $10 \mathrm{~m}$ wind speed and the incoming solar radiation (Seinfeld and Pandis,
2006). Wind, solar radiation, and $P_{\text {surf }}$ are all derived from the ERA5 reanalysis dataset (C3S, 2017), and $w$ is adopted from the OCO-2 files.

\subsection{Cross-sectional $\mathrm{CO}_{2}$ flux estimate}

We relate each satellite-observed $\mathrm{XCO}_{2}$ enhancement to anthropogenic emission sources within $50 \mathrm{~km}$ using the Gaussian plume model. We visually inspect the observed and modeled $\mathrm{XCO}_{2}$ and further select the ones that exhibit a single and isolated $\mathrm{CO}_{2}$ plume to attribute the plume to a neighbor cluster of emission sources and estimate the corresponding cross-sectional $\mathrm{CO}_{2}$ fluxes. We remove the linear background from the fitted curve of Eq. (1) and calculate the area under the remaining fitted curve to derive the $\mathrm{CO}_{2}$ line density ( $\mathrm{ppm} \mathrm{m}$ ), which can be converted to the unit of grams per meter through Eq. (3). The errors in the $\mathrm{CO}_{2}$ line densities are those of the area under the fitted curve, mainly driven by the random errors of the $\mathrm{XCO}_{2}$ retrievals and also by Eq. (1) that is not a perfect representation of actual $\mathrm{CO}_{2}$ plumes. The standard error statistics for each parameter in Eq. (1) are obtained from the weighted nonlinear least-squares fitting and propagated to calculate the uncertainties of the area under the fitted curve.

The $\mathrm{CO}_{2}$ line densities are multiplied by the wind speed $\left(\mathrm{m} \mathrm{s}^{-1}\right)$ in the direction normal to the OCO-2 tracks at the location of the plume peak to estimate cross-sectional $\mathrm{CO}_{2}$ fluxes $\left(\mathrm{g} \mathrm{s}^{-1}\right)$. The average wind below $500 \mathrm{~m}$ is used like in Eq. (2). To reduce the errors in the wind direction, we allow rotation of the wind direction within $45^{\circ}$ on each side of the ERA5 local wind direction to maximize the spatial correlation between the Gaussian plume-modeled and the OCO2-observed $\mathrm{XCO}_{2}$ according to Nassar et al. (2017). The derived cross-sectional $\mathrm{CO}_{2}$ fluxes approximately represent upwind source emissions under steady-state atmospheric conditions, while changes in the atmospheric stability (e.g., strong turbulent diffusion) could make the cross-sectional flux diverge from the source emissions (Varon et al., 2018; Reuter et al., 2019).

\section{Results}

\section{1 $\mathrm{CO}_{2}$ emission plumes seen by satellite}

The identification of $\mathrm{CO}_{2}$ emission plumes crossed by the satellite field of view starts with the search for $\mathrm{XCO}_{2}$ local enhancements. These are defined as $\mathrm{XCO}_{2}$ peaks above the background along the thin OCO-2 tracks. As shown in Fig. 1, we have identified a total of 6565 OCO-2 ground tracks over or around China between September 2014 and August 2019, with an even share between the cold-season (from September to February, $47 \%$ ) and the warm-season ones (from March to August, $53 \%$ ). We find 49322 cases with local $\mathrm{XCO}_{2}$ enhancements that exceed $2 \sigma$ above the local average in a $200 \mathrm{~km}$ wide moving window along the satellite tracks. How- 


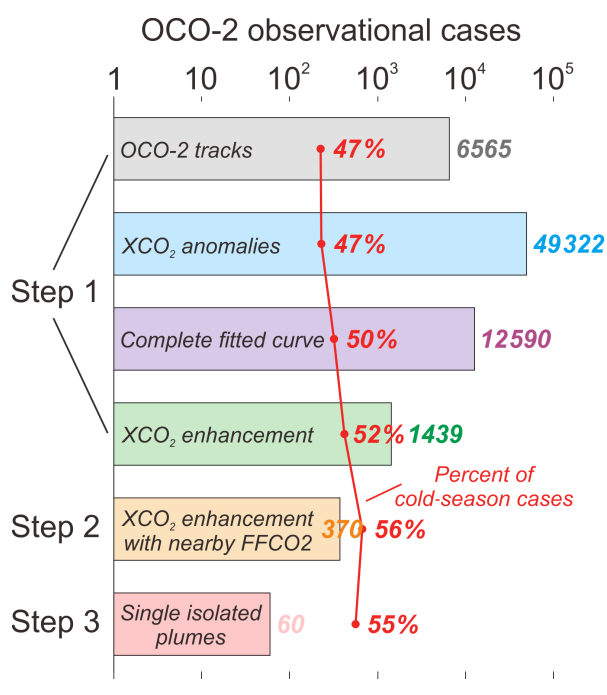

Figure 1. OCO-2 $\mathrm{XCO}_{2}$ observational cases contained in each processing step. Step 1 starts from 6565 OCO-2 tracks around and over China between September 2014 and August 2019 (grey bar) and finds $49322 \mathrm{XCO}_{2}$ anomalies along the OCO-2 tracks (blue bar). A total of 12590 anomalies (purple bar) and their surrounding data points within a $200 \mathrm{~km}$ wide window can be fitted by a complete nonlinear curve using Eq. (1), of which $1439 \mathrm{XCO}_{2}$ anomalies (green bar) are identified as a local enhancement significantly higher than the background. Step 2 uses the Gaussian plume model to select $370 \mathrm{XCO}_{2}$ enhancements (yellow bar) that can be traced back to upwind fossil fuel emission sources within $50 \mathrm{~km}$. In step 3 , we finally select the 60 cases with single isolated $\mathrm{CO}_{2}$ plumes to quantify the $\mathrm{CO}_{2}$ emissions. The red curve shows the percentage of cold-season observational cases in each bar. The detail of each step is described in Sect. 2.

ever, $97 \%$ of these $\mathrm{XCO}_{2}$ enhancements are removed after evaluation of the integrity of the plume section and of the spatial variation in surrounding background retrievals, leaving only $1439 \mathrm{XCO}_{2}$ cases as potent candidates for retrieving emissions.

The second step consists in attempting to attribute the observed $1439 \mathrm{CO}_{2}$ enhancements to nearby human emission sources. Only 370 of the $1439 \mathrm{XCO}_{2}$ local enhancements can be related to emission sources in the MEIC dataset using the Gaussian plume model within a $50 \mathrm{~km}$ upwind distance from each OCO-2 ground track. The other cases that reveal $\mathrm{XCO}_{2}$ enhancement but no nearby emission sources within $50 \mathrm{~km}$ upwind are probably due to either OCO-2 $\mathrm{XCO}_{2}$ retrieval errors at local scales, sources missing in MEIC, or transport of $\mathrm{CO}_{2}$ over a longer distance (Parazoo et al., 2011).

The third step is the quantification of cross-sectional $\mathrm{CO}_{2}$ fluxes within the satellite-observed $\mathrm{CO}_{2}$ plumes. Only 60 of the 370 cases correspond to single isolated $\mathrm{CO}_{2}$ plumes within a $200 \mathrm{~km}$ wide window, which allows unambiguous attribution to an emission site or cluster. One reason why we reject the other 310 cases is that they have two or more individual plumes, partially overlapping or separated. Some of the rejected cases also lack observation data of good quality (xco2_quality_flag equals 0 ) at a distance of several tens of kilometers due to significant retrieval errors in the local satellite observations.

The data filtering process retains more cold-season observations $(55 \%)$ than warm-season ones, in particular after the first step (52\% cases are from the cold season after the first step), due to favorable meteorological patterns during the cold season. Although the total number of selected cases is small, it is several times larger than in previous studies that only focused on large cities and large power plants in different locations of the world (Nassar et al., 2017; Reuter et al., 2019; Wu et al., 2020). The finally selected 60 cases include both densely populated urban areas (33 cases) and small industrial areas (27 cases) that gather many industrial plants. The peak height of $\mathrm{XCO}_{2}$ enhancement in the plumes $(A /(\sigma \sqrt{2 \pi})$ in Eq. 1$)$ is within 1.1-6.0 $\mu \mathrm{mol} \mathrm{mol}^{-1}$ (abbreviated as ppm) above the average local background and 27 times higher than the standard deviation of background levels within $200 \mathrm{~km}$. The width of observed $\mathrm{CO}_{2}$ plumes, defined as the full width at half maximum of peak height, is estimated between 2.2 and $61.2 \mathrm{~km}$.

\subsection{Quantifying $\mathrm{CO}_{2}$ emissions: one city example}

Figure 2 presents one example of the 60 selected cases. The emitter here is the city Anshan that has about 1.5 million inhabitants. On 17 October 2016, $\mathrm{CO}_{2}$ emissions from Anshan were blown southward by a $7.1 \mathrm{~m} \mathrm{~s}^{-1}$ wind at the OCO2 overpass time and generated an $\mathrm{XCO}_{2}$ local enhancement larger than $2 \mathrm{ppm}$ (Fig. 2). At about 13:30 local time, OCO-2 flew over the east of China (Fig. 2a), crossed the $\mathrm{CO}_{2}$ plume transported from Anshan, and successfully observed the local enhancement near the southernmost part of the OCO-2 ground track (Fig. 2b).

We plot the $\mathrm{XCO}_{2}$ retrieval data (grey dots in Fig. 2c) along the satellite ground track, the plot window of which is centered at the highest $\mathrm{XCO}_{2}$ value in the $\mathrm{CO}_{2}$ plume. We first fit the black curve $\left(R^{2}=0.4\right)$ based on Eq. (1) to depict the $\mathrm{CO}_{2}$ plume transect. The local background is represented by a straight line $-2.6 \times 10^{-3} \cdot x+402.1$ that approximates a flat background of $402.1 \mathrm{ppm}$. Then we subtract the background line from both the $\mathrm{XCO}_{2}$ data and the fitted black curve to obtain the net enhancement of $\mathrm{XCO}_{2}$ above the local background (pink dots and red curve in Fig. 2d). The maximum $\mathrm{XCO}_{2}$ net enhancement (peak height of the red curve) is $2.4 \mathrm{ppm}$ and the plume width is $15.0 \mathrm{~km}$. The $\mathrm{CO}_{2}$ line density is estimated as $0.60 \pm 0.04 \mathrm{t}-\mathrm{CO}_{2} \mathrm{~m}^{-1}$ (central estimate $\pm 1 \sigma$ ) by computing the area under the red curve (the orange shade in Fig. 2d). The uncertainty is mainly caused by random errors of the single $\mathrm{XCO}_{2}$ retrievals.

The $\mathrm{CO}_{2}$ line density derived from the satellite retrievals is further multiplied by the wind speed in the normal direction to the OCO-2 track to quantify the cross-sectional $\mathrm{CO}_{2}$ flux. We use the average wind below $500 \mathrm{~m}$ from the ERA5 reanal- 
(a)
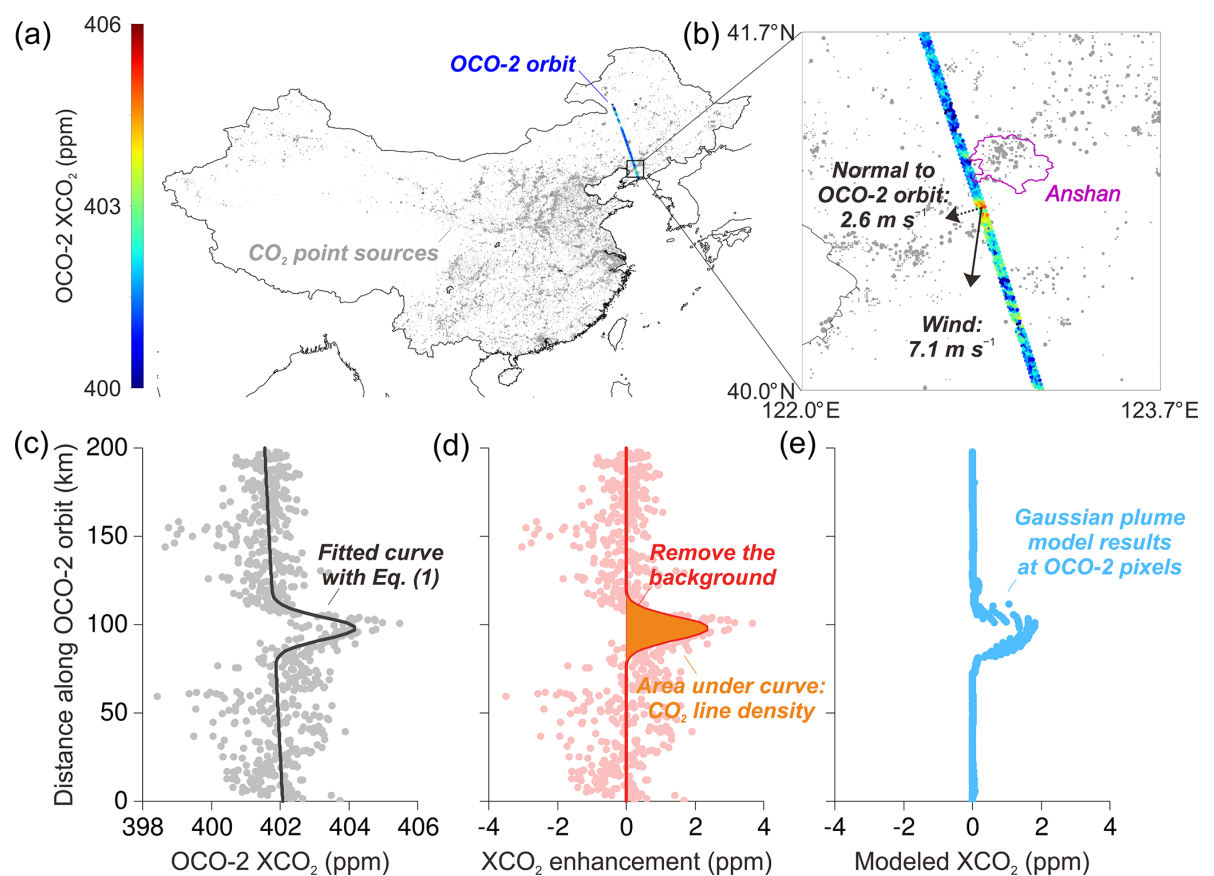

(e)

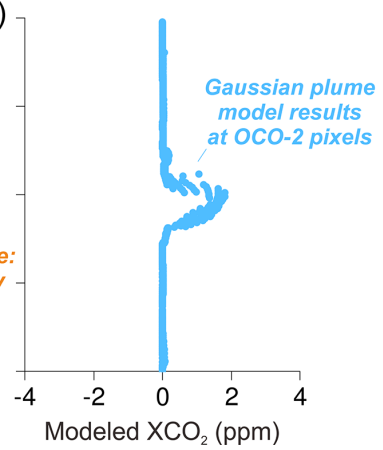

Figure 2. Quantification of $\mathrm{CO}_{2}$ emissions from Anshan. (a) The OCO-2 orbit on 17 October 2016 is plotted on the map of MEIC emission point sources. (b) Zoom in closer to see OCO-2 $\mathrm{XCO}_{2}$ data, local wind speed, and wind direction. The width of the track is made of eight cross-track OCO-2 footprints. (c) The valid $\mathrm{XCO}_{2}$ data points (grey dots) plotted along the OCO-2 orbit with a fitted curve (black) based on Eq. (1). (d) The $\mathrm{XCO}_{2}$ enhancement (red dots) above background, the fitted curve (red), and the area under the curve (orange shade). (e) The modeled $\mathrm{XCO}_{2}$ enhancement (blue dots) by the Gaussian plume model combined with the MEIC emission inventory.

ysis data. The ceiling height of $500 \mathrm{~m}$ is comparable to the maximum height that smoke plumes from power plants and industrial plants typically reach. The wind direction around Anshan is optimized according to Nassar et al. (2017) and is shifted by $1^{\circ}$ in this case to maximize the spatial correlation between the satellite-observed (Fig. 2d) and the modelsimulated (Fig. 2e) $\mathrm{XCO}_{2}$ enhancements. The wind speed in the normal direction to the OCO-2 track is then estimated as $2.6 \mathrm{~m} \mathrm{~s}^{-1}$ at the location of the maximum $\mathrm{XCO}_{2}$ value (Fig. 2b). The $\mathrm{CO}_{2}$ hourly flux at the satellite overpassing time is finally estimated as $5.7 \pm 1.2 \mathrm{kt}^{-} \mathrm{CO}_{2} \mathrm{~h}^{-1}$, considering uncertainties both in the $\mathrm{CO}_{2}$ line density and in the wind speed.

The satellite-observed $\mathrm{CO}_{2}$ plume can be traced back to anthropogenic emission sources located in the urbanized area of Anshan by the Gaussian plume model combined with the local emission map given by the MEIC inventory. We use monthly, weekly, and diurnal emission time profiles by region and by source sector from MEIC to split the annual emission totals reported by MEIC into hourly emission rates during the satellite overpass. The MEIC hourly emission rate of Anshan is $6.4 \pm 1.9 \mathrm{kt}-\mathrm{CO}_{2} \mathrm{~h}^{-1}$, which is close to the satellite-based inversion estimate.

\section{3 $\mathrm{CO}_{2}$ emission estimates for 60 cases in China}

We quantify the $\mathrm{CO}_{2}$ emissions corresponding to the 60 $\mathrm{CO}_{2}$ plumes selected from the 5-year OCO-2 archive. These represent 46 different urban areas or industrial regions in China. There are 14 regions whose emission plumes were observed twice in our selection of the satellite data. The 60 $\mathrm{CO}_{2}$ plumes present $\mathrm{CO}_{2}$ line densities between 0.1 and $2.8 \mathrm{t}-$ $\mathrm{CO}_{2} \mathrm{~m}^{-1}$, and hourly $\mathrm{CO}_{2}$ fluxes at the time of the satellite overpass are estimated within the range of $0.3-16.0 \mathrm{kt}$ $\mathrm{CO}_{2} \mathrm{~h}^{-1}$ with the $1 \sigma$ uncertainties of $20 \%-30 \%$. The larger sources tend to present lower relative uncertainties, because a larger $\mathrm{XCO}_{2}$ enhancement makes it easier to separate a plume from its background and is thus more easily observed by the satellite. The inversions that estimate $\mathrm{CO}_{2}$ emissions larger than $4 \mathrm{kt}-\mathrm{CO}_{2} \mathrm{~h}^{-1}$ tend to constrain their relative uncertainties below $25 \%$.

We compare the satellite-based $\mathrm{CO}_{2}$ hourly fluxes to the corresponding source emissions given by MEIC (Fig. 3), after applying emission time profiles to transform MEIC annual emissions into hourly emissions at the time of satellite overpass. Although the point-source-based MEIC emissions data are only for the year 2013, China's countrywide emissions remained stable between 2013 and 2017 and marginally grew only after 2017 (Friedlingstein et al., 2019). The satellite-based and MEIC-estimated emissions are broadly consistent within a factor of 2 (solid dots in 


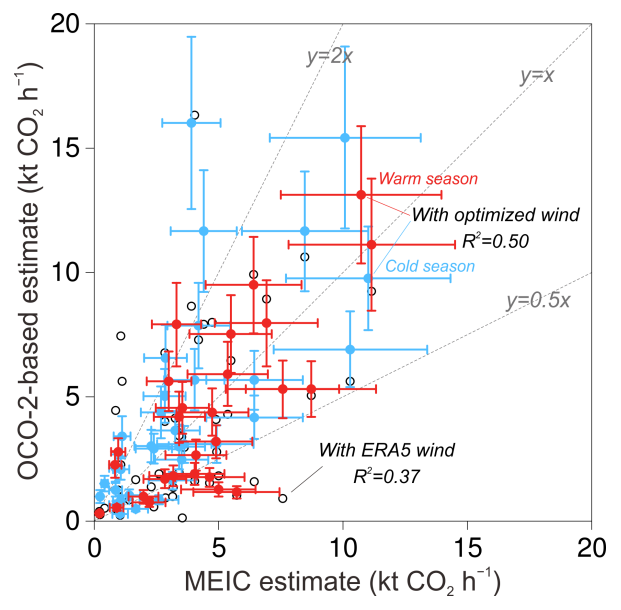

Figure 3. Comparison between OCO-2-based and MEIC-estimated $\mathrm{CO}_{2}$ hourly fluxes. Each dot represents one of the 60 plume cases selected in this study, plotted according to the MEIC-estimated $\mathrm{CO}_{2}$ flux ( $x$ axis) and the OCO-2-based estimate ( $y$ axis). The open dots are OCO-2 estimates using the ERA5 wind data, while the solid dots use the optimized wind and distinguish the warm-season (red dots) and the cold-season (blue dots) cases.

Fig. 3) with comparable uncertainties for the same individual estimates. The average of satellite-based estimates is $27.1 \%$ higher than the MEIC values in the cold season (solid blue dots in Fig. 3), while it is $5.2 \%$ lower in the warm season (solid red dots in Fig. 3).

The differences in the results between cold and warm seasons could be due to uncertainties in the emission estimate methods of both our OCO-2-based inversion and the MEIC inventory. The larger satellite-based estimates in the cold season could be partially due to the fact that human respiration contributes to urban $\mathrm{CO}_{2}$ fluxes while not included in the MEIC inventory of fossil fuel and cement emissions. We make a rough estimate of the metabolic $\mathrm{CO}_{2}$ release by multiplying an emission factor of $0.52 \mathrm{t}-\mathrm{CO}_{2} \mathrm{yr}^{-1}$ per person (Prairie and Duarte, 2007) by the population living in each emitting area. The results suggest that human metabolic $\mathrm{CO}_{2}$ emissions explain $8 \%$ of the larger satellite-based emission estimates on average in the cold season. The remaining difference could be due to the assumption that the $0-500 \mathrm{~m}$ average wind speed is representative of the transport wind in the plume diffusion, the natural processes like plant respiration, or the slight growth of fossil fuel emissions since 2013. However it could also reflect some bias in the MEIC estimates. In the warm season, despite human respiration emissions, the satellite-based inversions give lower emission estimates, possibly due to the carbon uptake by plants damping the $\mathrm{XCO}_{2}$ enhancements (Mitchell et al., 2018), which makes anthropogenic emission signals not easily separated from the background in the satellite-based inversions.

The uncertainties in the satellite-based emission estimates are driven by those of the local wind field and of the $\mathrm{CO}_{2}$ line density derived from the $\mathrm{XCO}_{2}$ retrievals. We reduce the errors in wind directions and consequently increase the $R^{2}$ of the linear correlation between satellite- and MEIC-based emission estimates across emitting areas from 0.37 (open dots) to 0.50 (solid dots) as shown in Fig. 3. The magnitude of the wind speed uncertainty, typically considered $10 \%$ $20 \%$ (Nassar et al., 2017; Varon et al., 2018; Reuter et al., 2019), is comparable to the uncertainty in the satellite-based $\mathrm{CO}_{2}$ line densities (3\%-23\% for the 60 emission plumes). In high-wind-speed conditions, the $\mathrm{CO}_{2}$ plumes are spread more quickly and thus cause smaller local enhancements, which weakens the signal of $\mathrm{XCO}_{2}$ and causes larger uncertainties in the estimate of $\mathrm{CO}_{2}$ line densities. Generally, our estimates reach lower relative uncertainties for largeremission cities under lower wind speeds.

\subsection{Comparison with global bottom-up inventories}

We extrapolate the satellite-based $\mathrm{CO}_{2}$ hourly fluxes to annual total fluxes using emission time profiles, and we compare them to two global bottom-up emission maps: ODIAC (Oda and Maksyutov, 2015; Oda et al., 2018) and EDGAR (Janssens-Maenhout et al., 2019). We use the cases between the years 2014 and 2018 when both inventories are available, and we extract $\mathrm{CO}_{2}$ emissions over each satellite-observed emitting area from the emission maps (Fig. 4). For the areas observed by the satellite in different years, we compute annual values from the corresponding inversions and average them for the comparison with ODIAC and EDGAR.

For individual estimates, ODIAC (Fig. 4b) and EDGAR (Fig. 4c) are broadly consistent with the annual budgets from the satellite-based inversions, but the fit is slightly better in the case of EDGAR. The large discrepancies are not surprising since global emission inventories typically involve large uncertainties at city scales (Gately and Hutyra, 2017; Gurney et al., 2019), because they disaggregate national emissions to gridded maps with simple proxies like population or nighttime light in the countries like China where they lack detailed direct local information. Only large power plants have exact geographic locations (from the CARMA global database; Wheeler and Ummel, 2008), in principle, but not all of the industrial plants like MEIC. ODIAC uses nightlights to disaggregate national emission estimates to grid cells, which may lead to an underestimation of road emissions in cities (Gately and Hutyra, 2017) and a misplacing of industrial emissions. EDGAR relies on point source locations to allocate emissions in space while it still suffers from missing local information in China, and gridded population maps have to be used instead. Such an emission mapping approach overestimates emissions over densely populated cities in China (Zheng et al., 2017), because the industry plants, the primary $\mathrm{CO}_{2}$ emission sources in China, are located far away from densely populated urban areas. The MEIC inventory estimates industrial emissions at the facility scale, transport emissions at the county scale, and residential emissions at the 

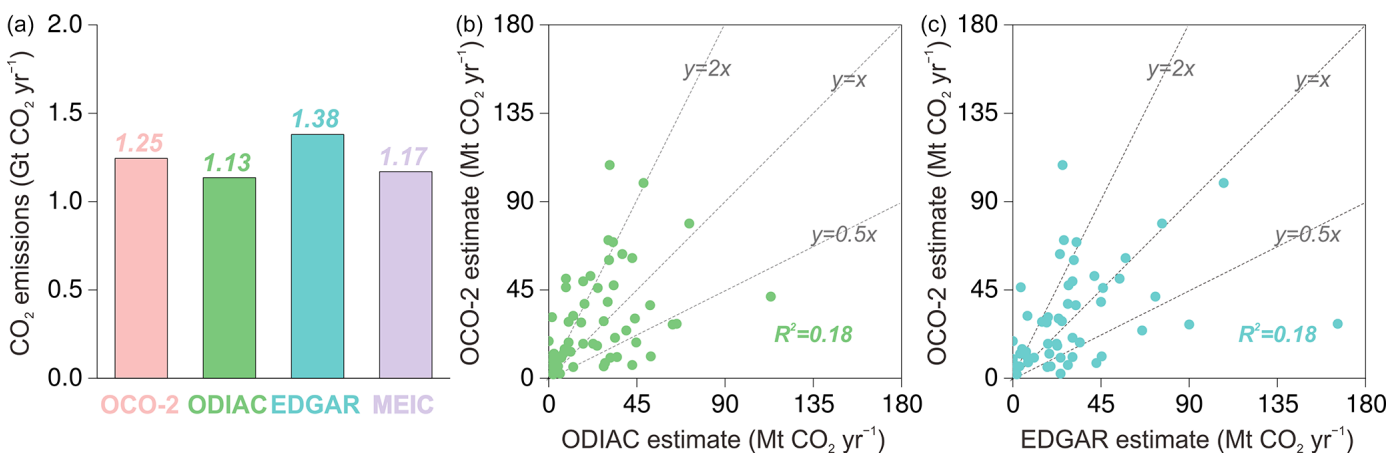

Figure 4. Comparing OCO-2-based $\mathrm{CO}_{2}$ emission estimates with bottom-up inventories. (a) The sum of emissions from the different regions observed by OCO-2 between the years 2014 and 2018, including OCO-2 estimates (scaled up to annual emissions based on MEIC emission time profiles, pink bar), ODIAC (green bar), EDGAR (blue bar), and MEIC (purple bar) estimates. (b) Comparison of regional CO $\mathrm{emissions}$ between OCO-2-based ( $y$ axis) and ODIAC estimates ( $x$ axis). (c) Comparison of regional $\mathrm{CO}_{2}$ emissions between OCO-2-based ( $y$ axis) and EDGAR estimates ( $x$ axis).

provincial scale, which can achieve better spatial accuracy in emissions estimates than the global emission inventories.

The sum of the emissions from the satellite-observed areas reaches $1.25 \mathrm{GtCO}_{2} \mathrm{yr}^{-1}$ (Fig. 4a), accounting for approximately $13 \%$ of the mainland China's total emissions. The corresponding bottom-up estimates from ODIAC, EDGAR, and MEIC are $1.13,1.38$, and $1.17 \mathrm{Gt} \mathrm{CO}_{2} \mathrm{yr}^{-1}$, respectively. ODIAC emissions are $9.6 \%$ lower than the satellite-based estimates while EDGAR emissions are $10.4 \%$ higher. The slight growth of the emissions from 2014 to 2018 (documented in, e.g., EDGAR) could alone mostly explain the $6 \%$ lower value for MEIC (valid for the year 2013) than the satellite estimate. Overall, EDGAR matches the individual estimates from the satellite-based inversions better than ODIAC for the $13 \%$ of mainland China's $\mathrm{CO}_{2}$ emissions that are observed by the satellite. However, both of these two global emission inventories reveal large uncertainties in emission estimates for individual areas as shown in Fig. $4 \mathrm{~b}$ and c.

\section{Conclusions}

We developed a novel objective approach to quantify local anthropogenic $\mathrm{CO}_{2}$ emissions from the OCO-2 $\mathrm{XCO}_{2}$ satellite retrievals. The key of this method is a conservative selection of the satellite data that can be safely exploited for emission quantification. It also depends on the wind information and the information about the locations of human emission sources in the upwind vicinity of the selected OCO-2 tracks. Future developments could aim at refining the stringent data selection, or at improving the estimation of wind speed or the description of the plume footprint, for instance using detailed regional atmospheric transport models. However the current simplicity of our approach makes it easily applicable everywhere over the globe, in principle. Our first regional analysis over mainland China suggests that $13 \%$ of its $\mathrm{CO}_{2}$ human emissions can be observed and constrained, to some extent, by 5 years of retrieval data from the OCO-2, a satellite instrument not designed for this task. The satellite-based emission inversion results are broadly consistent $\left(R^{2}=0.50\right.$, meaning we agree on broad classes of emitters) with the reliable point-source-based MEIC regional inventory despite our simple modeling of the plume and of its background and despite possible biases due to local non-fossil-fuel emissions or local sinks that contribute to the plume intensity. We also use the satellite-based estimates as a rough independent evaluation of two global bottom-up inventories, ODIAC and EDGAR.

There is still a large gap between what the satellite can see and the National Greenhouse Gas Inventory reports submitted to the United Nations Framework Convention on Climate Change (UNFCCC), mentioned at the start of the introduction. The former is made of specific emission plumes linked to recent emission events without any sectoral distinction within the plume. The latter is made of the country- and annual-scale emission values assigned to specific humancaused source-sink categories. The exhaustiveness of the MEIC inventory, which involved detailed analysis of the fine spatial and temporal emission patterns, allowed us to bridge most of this gap for a time period when Chinese emissions did not vary much, but few countries have such a detailed geospatial inventory of their emissions and are able to update it timely for such a task. We also acknowledge the limitations of the temporal emission profiles even from the detailed MEIC inventory. The sparse sampling of the OCO-2 instrument, despite the good precision of individual soundings, will partly be overcome by the next generation of $\mathrm{CO}_{2}$-dedicated imagery satellites, such as the $\mathrm{CO}_{2} \mathrm{Mon}$ itoring mission (CO2M) in Europe (Clery, 2019; JanssensMaenhout et al., 2020) and the Geostationary Carbon $\mathrm{Cy}$ cle Observatory (GeoCarb) in the US (Moore et al., 2018) that will have denser spatial coverage. However, their measurement principle still relies on sunlight and will prevent us from sampling the diurnal emission cycle well. The need for 
a good knowledge of the emission space-time patterns (not only the emission values) will therefore remain for the comparison between the national inventories and the satellitebased estimates. However, for countries with less advanced $\mathrm{CO}_{2}$ inventory infrastructures (typically non-Annex I parties to UNFCCC), we could also envisage an incremental approach where both bottom-up and top-down estimates are developed together in parallel.

Data availability. Version 9r of the OCO-2 bias-corrected $\mathrm{XCO}_{2}$ retrievals was downloaded from the data archive maintained at the NASA Goddard Earth Science Data and Information Services Center (https://oco2.gesdisc.eosdis.nasa.gov/data/s4pa/OCO2_DATA/ OCO2_L2_Lite_FP.9r/; Kiel et al., 2019). The ERA5 reanalysis data were acquired from the Copernicus Climate Change Service Climate Data Store (https://cds.climate.copernicus.eu/; C3S, 2017).

Author contributions. BZ, FC, and PC designed the study. BZ processed the observational data and estimated the $\mathrm{CO}_{2}$ fluxes from the satellite observations. BZ, FC, PC, and GB interpreted the results. $\mathrm{BZ}$ prepared the paper with contributions and suggestions from $\mathrm{FC}$, PC, GB, YW, JL, and YZ.

Competing interests. The authors declare that they have no conflict of interest.

Acknowledgements. The OCO-2 retrievals were produced by the OCO-2 project at the Jet Propulsion Laboratory, California Institute of Technology, and obtained from the OCO-2 data archive maintained at the NASA Goddard Earth Science Data and Information Services Center.

Review statement. This paper was edited by Ilse Aben and reviewed by two anonymous referees.

\section{References}

Beirle, S., Boersma, K. F., Platt, U., Lawrence, M. G., and Wagner, T.: Megacity Emissions and Lifetimes of Nitrogen Oxides Probed from Space, Science, 333, 1737-1739, https://doi.org/10.1126/science.1207824, 2011.

Bovensmann, H., Buchwitz, M., Burrows, J. P., Reuter, M., Krings, T., Gerilowski, K., Schneising, O., Heymann, J., Tretner, A., and Erzinger, J.: A remote sensing technique for global monitoring of power plant $\mathrm{CO}_{2}$ emissions from space and related applications, Atmos. Meas. Tech., 3, 781-811, https://doi.org/10.5194/amt-3781-2010, 2010.

Broquet, G., Bréon, F.-M., Renault, E., Buchwitz, M., Reuter, M., Bovensmann, H., Chevallier, F., Wu, L., and Ciais, P.: The potential of satellite spectro-imagery for monitoring $\mathrm{CO}_{2}$ emissions from large cities, Atmos. Meas. Tech., 11, 681-708, https://doi.org/10.5194/amt-11-681-2018, 2018.
Chevallier, F.: Comment on "Contrasting carbon cycle responses of the tropical continents to the 2015-2016 El Niño", Science, 362, eaar5432, https://doi.org/10.1126/science.aar5432, 2018.

Clery, D.: Space budget boost puts Europe in lead to monitor carbon from space, Science, https://doi.org/10.1126/science.aba4530, 2019.

Copernicus Climate Change Service (C3S): ERA5: Fifth generation of ECMWF atmospheric reanalyses of the global climate, Copernicus Climate Change Service Climate Data Store (CDS), https:// cds.climate.copernicus.eu/cdsapp\#!/home (last access: 12 February 2020), 2017.

Eldering, A., Wennberg, P. O., Crisp, D., Schimel, D. S., Gunson, M. R., Chatterjee, A., Liu, J., Schwandner, F. M., Sun, Y., O'Dell, C. W., Frankenberg, C., Taylor, T., Fisher, B., Osterman, G. B., Wunch, D., Hakkarainen, J., Tamminen, J., and Weir, B.: The Orbiting Carbon Observatory-2 early science investigations of regional carbon dioxide fluxes, Science, 358, eaam5745, https://doi.org/10.1126/science.aam5745, 2017.

Friedlingstein, P., Jones, M. W., O’Sullivan, M., Andrew, R. M., Hauck, J., Peters, G. P., Peters, W., Pongratz, J., Sitch, S., Le Quéré, C., Bakker, D. C. E., Canadell, J. G., Ciais, P., Jackson, R. B., Anthoni, P., Barbero, L., Bastos, A., Bastrikov, V., Becker, M., Bopp, L., Buitenhuis, E., Chandra, N., Chevallier, F., Chini, L. P., Currie, K. I., Feely, R. A., Gehlen, M., Gilfillan, D., Gkritzalis, T., Goll, D. S., Gruber, N., Gutekunst, S., Harris, I., Haverd, V., Houghton, R. A., Hurtt, G., Ilyina, T., Jain, A. K., Joetzjer, E., Kaplan, J. O., Kato, E., Klein Goldewijk, K., Korsbakken, J. I., Landschützer, P., Lauvset, S. K., Lefèvre, N., Lenton, A., Lienert, S., Lombardozzi, D., Marland, G., McGuire, P. C., Melton, J. R., Metzl, N., Munro, D. R., Nabel, J. E. M. S., Nakaoka, S.-I., Neill, C., Omar, A. M., Ono, T., Peregon, A., Pierrot, D., Poulter, B., Rehder, G., Resplandy, L., Robertson, E., Rödenbeck, C., Séférian, R., Schwinger, J., Smith, N., Tans, P. P., Tian, H., Tilbrook, B., Tubiello, F. N., van der Werf, G. R., Wiltshire, A. J., and Zaehle, S.: Global Carbon Budget 2019, Earth Syst. Sci. Data, 11, 1783-1838, https://doi.org/10.5194/essd-111783-2019, 2019.

Gately, C. K. and Hutyra, L. R.: Large Uncertainties in Urban-Scale Carbon Emissions, J. Geophys. Res.-Atmos., 122, 11242-11260, https://doi.org/10.1002/2017jd027359, 2017.

Gurney, K. R., Liang, J., O’Keeffe, D., Patarasuk, R., Hutchins, M., Huang, J., Rao, P., and Song, Y.: Comparison of Global Downscaled Versus Bottom-Up Fossil Fuel $\mathrm{CO}_{2}$ Emissions at the Urban Scale in Four U.S. Urban Areas, J. Geophys. Res.-Atmos., 124, 2823-2840, https://doi.org/10.1029/2018jd028859, 2019.

IPCC (Intergovernmental Panel on Climate Change): 2019 Refinement to the 2006 IPCC Guidelines for National Greenhouse Gas Inventories, available at: https://www.ipcc-nggip.iges.or.jp/ public/2019rf/ (last access: 19 July 2020), 2019.

Janssens-Maenhout, G., Crippa, M., Guizzardi, D., Muntean, M., Schaaf, E., Dentener, F., Bergamaschi, P., Pagliari, V., Olivier, J. G. J., Peters, J. A. H. W., van Aardenne, J. A., Monni, S., Doering, U., Petrescu, A. M. R., Solazzo, E., and Oreggioni, G. D.: EDGAR v4.3.2 Global Atlas of the three major greenhouse gas emissions for the period 1970-2012, Earth Syst. Sci. Data, 11, 959-1002, https://doi.org/10.5194/essd-11-959-2019, 2019.

Janssens-Maenhout, G., Pinty, B., Dowell, M., Zunker, H., Andersson, E., Balsamo, G., Bézy, J.-L., Brunhes, T., Bösch, H., Bojkov, B., Brunner, D., Buchwitz, M., Crisp, D., Ciais, P., Counet, 
P., Dee, D., Denier van der Gon, H., Dolman, H., Drinkwater, M., Dubovik, O., Engelen, R., Fehr, T., Fernandez, V., Heimann, M., Holmlund, K., Houweling, S., Husband, R., Juvyns, O., Kentarchos, A., Landgraf, J., Lang, R., Löscher, A., Marshall, J., Meijer, Y., Nakajima, M., Palmer, P. I., Peylin, P., Rayner, P., Scholze, M., Sierk, B., Tamminen, J., and Veefkind, P.: Towards an operational anthropogenic $\mathrm{CO}_{2}$ emissions monitoring and verification support capacity, B. Am. Meteorol. Soc., https://doi.org/10.1175/bams-d-19-0017.1, online first, 2020.

Kiel, M., O’Dell, C. W., Fisher, B., Eldering, A., Nassar, R., MacDonald, C. G., and Wennberg, P. O.: How bias correction goes wrong: measurement of $\mathrm{X}_{\mathrm{CO}_{2}}$ affected by erroneous surface pressure estimates, Atmos. Meas. Tech., 12, 2241-2259, https://doi.org/10.5194/amt-12-2241-2019, 2019 (data available at: https://oco2.gesdisc.eosdis.nasa.gov/data/s4pa/OCO2_ DATA/OCO2_L2_Lite_FP.9r/, last access: 12 February 2020).

Kort, E. A., Frankenberg, C., Miller, C. E., and Oda, T.: Space-based observations of megacity carbon dioxide, Geophys. Res. Lett., 39, L17806, https://doi.org/10.1029/2012g1052738, 2012.

Kuhlmann, G., Broquet, G., Marshall, J., Clément, V., Löscher, A., Meijer, Y., and Brunner, D.: Detectability of $\mathrm{CO}_{2}$ emission plumes of cities and power plants with the Copernicus Anthropogenic $\mathrm{CO}_{2}$ Monitoring (CO2M) mission, Atmos. Meas. Tech., 12, 6695-6719, https://doi.org/10.5194/amt-126695-2019, 2019.

Labzovskii, L. D., Jeong, S.-J., and Parazoo, N. C.: Working towards confident spaceborne monitoring of carbon emissions from cities using Orbiting Carbon Observatory-2, Remote Sens. Environ., 233, 111359, https://doi.org/10.1016/j.rse.2019.111359, 2019.

Liu, J., Bowman, K. W., Schimel, D. S., Parazoo, N. C., Jiang, Z., Lee, M., Bloom, A. A., Wunch, D., Frankenberg, C., Sun, Y., O’Dell, C. W., Gurney, K. R., Menemenlis, D., Gierach, M., Crisp, D., and Eldering, A.: Contrasting carbon cycle responses of the tropical continents to the 2015-2016 El Niño, Science, 358, eaam5690, https://doi.org/10.1126/science.aam5690, 2017.

Martin, D. O.: Comment On "The Change of Concentration Standard Deviations with Distance", JAPCA J. Air Waste Ma., 26, 145-147, https://doi.org/10.1080/00022470.1976.10470238, 1976.

Mitchell, L. E., Lin, J. C., Bowling, D. R., Pataki, D. E., Strong, C., Schauer, A. J., Bares, R., Bush, S. E., Stephens, B. B., Mendoza, D., Mallia, D., Holland, L., Gurney, K. R., and Ehleringer, J. R.: Long-term urban carbon dioxide observations reveal spatial and temporal dynamics related to urban characteristics and growth, P. Natl. Acad. Sci. USA, 115, 2912-2917, https://doi.org/10.1073/pnas.1702393115, 2018.

Moore III, B., Crowell, S. M. R., Rayner, P. J., Kumer, J., O’Dell, C. W., O'Brien, D., Utembe, S., Polonsky, I., Schimel, D., and Lemen, J.: The Potential of the Geostationary Carbon Cycle Observatory (GeoCarb) to Provide Multi-scale Constraints on the Carbon Cycle in the Americas, Front. Environ. Sci., 6, 109, https://doi.org/10.3389/fenvs.2018.00109, 2018.

Nassar, R., Hill, T. G., McLinden, C. A., Wunch, D., Jones, D. B. A., and Crisp, D.: Quantifying $\mathrm{CO}_{2}$ Emissions From Individual Power Plants From Space, Geophys. Res. Lett., 44, 1004510053, https://doi.org/10.1002/2017g1074702, 2017.

O'Brien, D. M., Polonsky, I. N., Utembe, S. R., and Rayner, P. J.: Potential of a geostationary geoCARB mission to estimate sur- face emissions of $\mathrm{CO}_{2}, \mathrm{CH}_{4}$ and $\mathrm{CO}$ in a polluted urban environment: case study Shanghai, Atmos. Meas. Tech., 9, 4633-4654, https://doi.org/10.5194/amt-9-4633-2016, 2016.

Oda, T. and Maksyutov, S.: ODIAC Fossil Fuel $\mathrm{CO}_{2}$ Emissions Dataset (ODIAC2019), Center for Global Environmental Research, National Institute for Environmental Studies, https://doi.org/10.17595/20170411.001, 2015.

Oda, T., Maksyutov, S., and Andres, R. J.: The Open-source Data Inventory for Anthropogenic $\mathrm{CO}_{2}$, version 2016 (ODIAC2016): a global monthly fossil fuel $\mathrm{CO}_{2}$ gridded emissions data product for tracer transport simulations and surface flux inversions, Earth Syst. Sci. Data, 10, 87-107, https://doi.org/10.5194/essd-10-872018, 2018.

Palmer, P. I., Feng, L., Baker, D., Chevallier, F., Bösch, H., and Somkuti, P.: Net carbon emissions from African biosphere dominate pan-tropical atmospheric $\mathrm{CO}_{2}$ signal, Nat. Commun., 10, 3344, https://doi.org/10.1038/s41467-019-11097-w, 2019.

Parazoo, N. C., Denning, A. S., Berry, J. A., Wolf, A., Randall, D. A., Kawa, S. R., Pauluis, O., and Doney, S. C.: Moist synoptic transport of $\mathrm{CO}_{2}$ along the mid-latitude storm track, Geophys. Res. Lett., 38, L09804, https://doi.org/10.1029/2011g1047238, 2011.

Prairie, Y. T. and Duarte, C. M.: Direct and indirect metabolic $\mathrm{CO}_{2}$ release by humanity, Biogeosciences, 4, 215-217, https://doi.org/10.5194/bg-4-215-2007, 2007.

Reuter, M., Buchwitz, M., Schneising, O., Krautwurst, S., O’Dell, C. W., Richter, A., Bovensmann, H., and Burrows, J. P.: Towards monitoring localized $\mathrm{CO}_{2}$ emissions from space: colocated regional $\mathrm{CO}_{2}$ and $\mathrm{NO}_{2}$ enhancements observed by the OCO-2 and S5P satellites, Atmos. Chem. Phys., 19, 9371-9383, https://doi.org/10.5194/acp-19-9371-2019, 2019.

Schwandner, F. M., Gunson, M. R., Miller, C. E., Carn, S. A., Eldering, A., Krings, T., Verhulst, K. R., Schimel, D. S., Nguyen, H. M., Crisp, D., O’Dell, C. W., Osterman, G. B., Iraci, L. T., and Podolske, J. R.: Spaceborne detection of localized carbon dioxide sources, Science, 358, eaam5782, https://doi.org/10.1126/science.aam5782, 2017.

Seinfeld, J. H. and Pandis, S. N.: Atmospheric chemistry and physics: from air pollution to climate change, John Wiley \& Sons, Inc., Hoboken, USA, p. 750, 2006.

UNFCCC (United Nation Framework Convention on Climate Change): Decision 18/CMA.1 Modalities, procedures and guidelines for the transparency framework for action and support referred to in Article 13 of the Paris Agreement, FCCC/PA/CMA/2018/Add.2, available at: https://unfccc.int/ sites/default/files/resource/cma2018_3_add2_new_advance.pdf (last access: 19 July 2020), 2018.

Varon, D. J., Jacob, D. J., McKeever, J., Jervis, D., Durak, B. O. A., Xia, Y., and Huang, Y.: Quantifying methane point sources from fine-scale satellite observations of atmospheric methane plumes, Atmos. Meas. Tech., 11, 5673-5686, https://doi.org/10.5194/amt-11-5673-2018, 2018

Wang, Y., Broquet, G., Bréon, F.-M., Lespinas, F., Buchwitz, M., Reuter, M., Meijer, Y., Loescher, A., Janssens-Maenhout, G., Zheng, B., and Ciais, P.: PMIF v1.0: an inversion system to estimate the potential of satellite observations to monitor fossil fuel $\mathrm{CO}_{2}$ emissions over the globe, Geosci. Model Dev. Discuss., https://doi.org/10.5194/gmd-2019-326, in review, 2020. 
Wheeler, D. and Ummel, K.: Calculating Carma: Global Estimation of $\mathrm{CO}_{2}$ Emissions from the Power Sector, SSRN, https://doi.org/10.2139/ssrn.1138690, 2008.

Worden, J. R., Doran, G., Kulawik, S., Eldering, A., Crisp, D., Frankenberg, C., O'Dell, C., and Bowman, K.: Evaluation and attribution of OCO- $2 \mathrm{XCO}_{2}$ uncertainties, Atmos. Meas. Tech., 10, 2759-2771, https://doi.org/10.5194/amt-10-2759-2017, 2017.

Wu, D., Lin, J., Oda, T., and Kort, E.: Space-based quantification of per capita $\mathrm{CO}_{2}$ emissions from cities, Environ. Res. Lett., 15, 035004, https://doi.org/10.1088/1748-9326/ab68eb, 2020.

Zheng, B., Zhang, Q., Tong, D., Chen, C., Hong, C., Li, M., Geng, G., Lei, Y., Huo, H., and He, K.: Resolution dependence of uncertainties in gridded emission inventories: a case study in Hebei, China, Atmos. Chem. Phys., 17, 921-933, https://doi.org/10.5194/acp-17-921-2017, 2017.
Zheng, B., Tong, D., Li, M., Liu, F., Hong, C., Geng, G., Li, H., Li, X., Peng, L., Qi, J., Yan, L., Zhang, Y., Zhao, H., Zheng, Y., He, K., and Zhang, Q.: Trends in China's anthropogenic emissions since 2010 as the consequence of clean air actions, Atmos. Chem. Phys., 18, 14095-14111, https://doi.org/10.5194/acp-18-140952018, 2018a.

Zheng, B., Zhang, Q., Davis, S. J., Ciais, P., Hong, C., Li, M., Liu, F., Tong, D., Li, H., and He, K.: Infrastructure Shapes Differences in the Carbon Intensities of Chinese Cities, Environ. Sci. Technol., 52, 6032-6041, https://doi.org/10.1021/acs.est.7b05654, 2018b.

Zheng, T., Nassar, R., and Baxter, M.: Estimating power plant $\mathrm{CO}_{2}$ emission using OCO-2 $\mathrm{XCO}_{2}$ and high resolution WRF-Chem simulations, Environ. Res. Lett., 14, 085001, https://doi.org/10.1088/1748-9326/ab25ae, 2019. 